\title{
Breath-shield modification on Haag-Streit slit lamp
}

\section{G. J. ROMANES}

Post-Graduate Medical Centre, Dorchester, and Royal Eye Infirmary, Weymouth, Dorset

The presbyopic user of the current Haag-Streit Slit Lamp Model goo is unable to read easily the result of applanation tonometry under the normal conditions of illumination

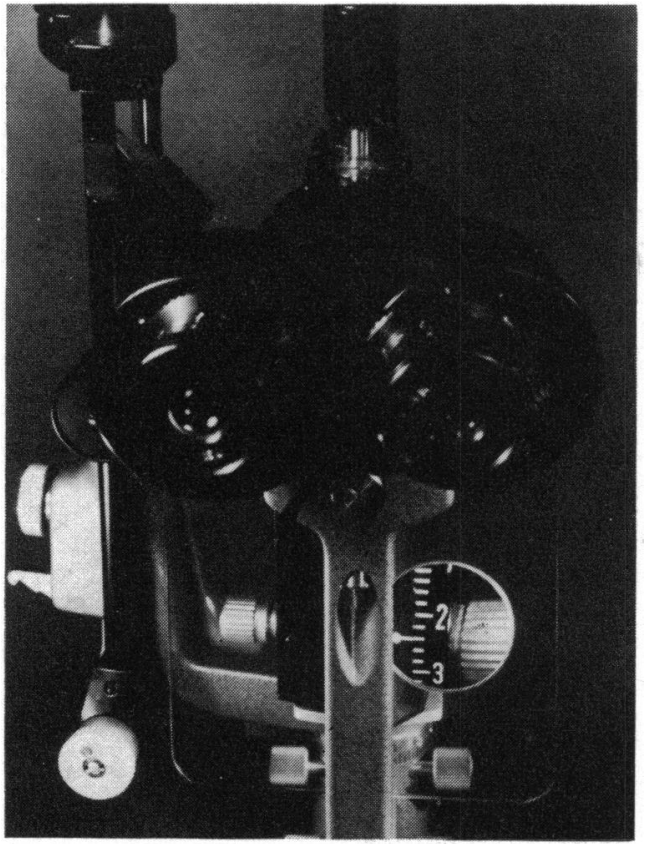

FIGURE Spherical lens in use with slit lamp breath shield in the darkened consulting room. He has to increase the room lighting, put on his correcting glasses, or may perhaps be able to sit back and so focus the scale sufficiently to read it. These difficulties can be overcome by a simple modification to the breath shield of the slit lamp.

A $+4 \mathrm{D}$ spherical lens is fixed to the shield in such a position that the scale can be read by the observer, who has merely to drop his visual axis and look with his right eye. The lens is large enough to cover the scale with the Model $\mathrm{T}$ applanation tonometer in the right or left location slot. It also suits the Model $\mathbf{R}$ tonometer which is attached to the slit lamp by a suspensory arm, so that the left eye is used for determination of the applanation images. The lens helps observers with moderate refractive errors both hypermetropic and myopic. If it happens to interfere, the breath shield can be reversed and the tonometer read normally.

I am indebted to Mr. H. J. Stockwell of Messrs. Instrumedic Limited who has helped to develop this accessory, and from whom it is now available. 